\title{
$\mathrm{M}|\mathrm{R}| \mathrm{S}$ Internet Journal Nitride Semiconductor Research
}

\section{Effect Of Implantation Temperature On Damage Accumulation In Ar - Implanted GaN}

\author{
I. Usov ${ }^{1}$, N. Parikh ${ }^{1}$, D.B. Thomson ${ }^{2}$ and Robert F. Davis ${ }^{2}$ \\ ${ }^{1}$ Curriculum in Applied and Materials Sciences, University of North Carolina at Chapel Hill, \\ ${ }^{2}$ Department of Materials Science and Engineering, North Carolina State University,
}

(Received Wednesday, October 9, 2002; accepted Tuesday, December 17, 2002)

A systematic investigation of damage accumulation in $\mathrm{GaN}$ films induced by $\mathrm{Ar}^{+}$as a function of implantation temperature and dose rate has been conducted. Depth distribution of disorder was measured by Rutherford Backscattering/Channeling spectrometry. Two disordered regions were identified in the damage depth distribution: a surface peak and a bulk damage peak. These regions exhibited different behavior as a function of implantation temperature. The displaced atomic density in the bulk damage peak displayed a "reverse annealing" behavior in temperature range from $500{ }^{\circ} \mathrm{C}$ to $700{ }^{\circ} \mathrm{C}$, which we attributed to formation of characteristic secondary defects. The influence of implantation temperature and dose rate on the radiation damage accumulation is discussed.

\section{Introduction}

Due to its outstanding properties, GaN plays a significant role in modern semiconductor physics and technology. In order to realize the advantage of $\mathrm{GaN}$, controllable doping and formation of semi insulating layers must be achieved. Ion implantation is the only technique presently available for planar selective area doping of GaN [1]. The introduction of dopants into solids by ion implantation is accompanied by radiation damage of the crystalline lattice, which has to be recovered via annealing treatments. It has been demonstrated that the removal of implantation damage in $\mathrm{GaN}$ requires annealing temperatures above $1500{ }^{\circ} \mathrm{C}$ and is complicated by material decomposition due to nitrogen evaporation [2]. One way to facilitate the annealing process is to reduce the damage concentration by performing the ion implantation at elevated temperatures. It has been shown in a number of papers that ion implantation at temperatures $\left(\mathrm{T}_{\mathrm{imp}}\right)$ up to $550{ }^{\circ} \mathrm{C}$ reduces the amount of radiation damage in comparison to room temperature (RT) [3] [4] [5]. In contrast, a report by Wenzel et al. [6] indicated that the lattice disorder measured by Rutherford Backscattering/Channeling spectrometry (RBS/ C) in $\mathrm{GaN}$ implanted with $\mathrm{Mg}^{+}$increased with increasing implantation temperature from RT to $550{ }^{\circ} \mathrm{C}$. The main intention of the present study, therefore, was to investigate in detail the dependence on the implantation temperature of the amount of damage produced in $\mathrm{GaN}$ over a wide temperature range.

\section{Experimental Details}

For the present investigation, epitaxial GaN films (1.0 $1.5 \mu \mathrm{m}$ thick) were grown on (0001) $6 \mathrm{H}-\mathrm{SiC}$ substrates by MOVPE deposition. Implantation with $150 \mathrm{keV} \mathrm{Ar}^{+}$ was performed at temperatures ranging from RT to 1000 ${ }^{\circ} \mathrm{C}$, to a dose of $3 \times 10^{15} \mathrm{~cm}^{-2}$ and a dose rate 0.45 and 4.5 $\mu \mathrm{A} / \mathrm{cm}^{2}$. During implantation the tilt angle between the ion beam direction and the sample surface was set to $5^{\circ}$ to avoid channeling effects. Samples were mounted onto a graphite strip, which was heated by passing an AC current through it. The heater temperature calibration was carried out by an optical pyrometer and $\mathrm{Pt} / \mathrm{Pt}-10 \% \mathrm{Rh}$ thermocouple. The ion-induced damage was determined by means of $\mathrm{RBS} / \mathrm{C}$ with $2.3 \mathrm{MeV} \mathrm{He}^{+}$ions aligned along <0001> axis of the GaN sample and a scattering angle of $108^{\circ}$.

\section{Results and Discussions}

Figures 1a - 1c depict the aligned RBS spectra obtained from the as-grown sample and from samples that were implanted with $150 \mathrm{keV} \mathrm{Ar}^{+}$to the dose of $3 \times 10^{15} \mathrm{~cm}^{-2}$ at the dose rate $0.45 \mu \mathrm{A} / \mathrm{cm}^{2}$ over the temperature range from RT to $1000{ }^{\circ} \mathrm{C}$. For visualization of the RBS/C spectra, the temperature range has been divided into three groups and the data are shown in separate plots. A 
significant feature in these figures is that the yield of backscattering ions shows two distinct regions, which behave differently with the change of implantation temperature. The first region corresponds to the sharp surface peak, which arose from the scattering from $\mathrm{Ga}$ atoms located at the sample surface and reflects an amount of disorder on the surface. The height of the surface peak decreases with increasing implantation temperature and approaches the magnitude of the unimplanted sample. The second region is located at the energies $1.6-1.9 \mathrm{MeV}$ and represents the peak resulting from direct scattering from the displaced $\mathrm{Ga}$ atoms in the sample bulk. The figures clearly show that backscattering yield in the bulk peak region decrease with increasing $\mathrm{T}_{\text {imp }}$ up to $500{ }^{\circ} \mathrm{C}$ (see Figure 1a). Implantation at higher temperatures results in a retrograde behavior of the backscattering yield with temperature. Irradiation in the temperature range between $500{ }^{\circ} \mathrm{C}$ and $700{ }^{\circ} \mathrm{C}$ leads to an increase in the yield (see Figure 1b), which we refer to as the "reverse annealing" regime and further increase of the temperature decreases the backscattering yield (see Figure 1c).

These results are very unexpected because usually, as the implantation temperature increases one observes a decrease of disorder. RBS/C studies of $\mathrm{Si}, \mathrm{Ge}$ and GaAs implanted at elevated temperatures with various ions, at a wide range of energies and ion doses have demonstrated that an increase of the implantation temperature always results in a decrease of the concentration of radiation-induced defects [7] [8] [9]. We believe that the retrograde behavior of the damage density as a function of implantation temperature observed in $\mathrm{GaN}$ is due to the fact that damage accumulation under bombardment in this material proceeds by a mechanism different from the mechanism which takes place in the above-mentioned materials. It is plausible that, due to the high dynamic annealing rate, characteristic secondary defects are formed in the narrow temperature interval just before the temperature at which the disorder begins to drop, and that these defects cause significant displacement of atoms from regular lattice sites, as registered by $\mathrm{RBS} / \mathrm{C}$.

The depth distribution of defects in the bulk damage peak, $\mathrm{N}_{\mathrm{d}}(\mathrm{z})$, was estimated by applying the linear dechanneling approximation [10]:

$$
\mathrm{N}_{\mathrm{d}}(\mathrm{z})=\mathrm{N}_{0}\left[\frac{\chi_{\mathrm{d}}(\mathrm{z})-\chi_{\mathrm{r}}(\mathrm{z})}{1-\chi_{\mathrm{r}}(\mathrm{z})}\right]
$$

where $\mathrm{N}_{0}$ is the atomic density in the Ga sublattice, $\chi_{\mathrm{d}}$ and $\chi_{\mathrm{r}}$ are the measured normalized yield in the dam- aged crystal and the calculated dechanneled fraction, respectively.

The defect profiles obtained from equation (1) are shown in Figures $2 a-2 c$. The bulk damage peak resembles a Gaussian-like profile centered at $90 \pm 10 \mathrm{~nm}$ for $\mathrm{T}_{\text {imp }}$ up to $500{ }^{\circ} \mathrm{C}$ (see Figure 2a). The increase of $\mathrm{T}_{\text {imp }}$ from RT to $500{ }^{\circ} \mathrm{C}$ results not only in annihilation of radiation defects but also in their diffusion into the sample bulk. When the implantation conditions favorable for the reverse annealing regime were achieved, the maximum of the damage peak shifted deeper into the bulk and was situated at $113 \pm 10 \mathrm{~nm}$ for irradiation at $T_{i m p}=$ $700{ }^{\circ} \mathrm{C}$ (see Figure 2b). Further increase of implantation temperature to $1000{ }^{\circ} \mathrm{C}$ reduces the amount of disorder (see Figure 2c). At $\mathrm{T}_{\mathrm{imp}} \geq 800{ }^{\circ} \mathrm{C}$ the maximum of the bulk damage peak shifts back to the surface, presumably due to evaporation of a thin surface layer. Analysis of $\mathrm{GaN}$ evaporation during high-temperature ion implantation will be reported elsewhere.

We believe that the reverse annealing characteristic is directly related to the shift of the maximum of radiation damage into the bulk from the depth of the primary defects, which corresponds to the maximum of the nuclear energy loss towards the projected range $\left(R_{p}\right)$ of Ar ions. As the implantation temperature increases the mobility of point defects, lattice and impurity atoms also increases. Since the concentration of Ar atoms at $R_{p}$ was relatively high $(\sim 0.4$ at $\%)$ and its solubility is low, the stressed region with high Ar concentration may serve as a nucleation site for secondary defects. Thus it is conceivable that the increase of the damage in the temperature range between $500{ }^{\circ} \mathrm{C}$ and $700{ }^{\circ} \mathrm{C}$ is related to the build up of these secondary defects in the implanted layer.

A similar phenomenon was observed in $\mathrm{GaN}$ implanted at temperatures ranging from RT to $550{ }^{\circ} \mathrm{C}$ with $2.5 \times 10^{15} \mathrm{~cm}^{-2} \mathrm{Mg}^{+}$at the dose rate up to $20 \mu \mathrm{A} /$ $\mathrm{cm}^{2}$ [6]. The authors observed that backscattering yield increased with increasing irradiation temperature and suggested that this behavior is due to defects generated at high implantation temperatures. We believe that the same type of defects are responsible for the reverse annealing behavior for $\mathrm{Ar}^{+}$and $\mathrm{Mg}^{+}$irradiation of $\mathrm{GaN}$, and that the different temperature range of this phenomenon is dictated by the magnitude of the dose rate, which was significantly higher in [6] than in our experiments. To check this, the dose rate was increased up to $4.5 \mu \mathrm{A} / \mathrm{cm}^{2}$ and the other implantation conditions were kept the same.

The integrated defect density, $\mathrm{I}_{\mathrm{d}}$, in the bulk damage peak and the height of the surface peak, $\mathrm{H}_{\mathrm{sp}}$, as a function of the implantation temperature for two different 
dose rates are shown in Figure 3. The magnitude of $\mathrm{H}_{\mathrm{sp}}$ decreases monotonically with temperature and there is little difference in the amount of disorder produced at different dose rates. However, the impact of the dose rate is apparent if one considers the disorder in the bulk damage peak. The shape of the $\mathrm{I}_{\mathrm{d}}(\mathrm{T})$ dependencies at both dose rates is very similar, but the retrograde behavior is shifted by $\sim 100{ }^{\circ} \mathrm{C}$ towards lower temperatures at the higher dose rate value. We believe that there was extra heating of the samples during the implantations at $4.5 \mu \mathrm{A} / \mathrm{cm}^{2}$. This temperature rise was not recorded because the thermocouple was not exposed to the ion beam and was not attached to the sample surface but to the backside of the heater. Thus it is possible that the shift of the $I_{d}(T)$ dependence observed in Figure 3 resulted from the rise of actual sample temperature during the high dose rate irradiation.

Taking into account the temperature increase caused by high dose rate beam, one can explain the other discrepancies observed in Figure 3. For example, the decrease of the $\mathrm{H}_{\mathrm{sp}}\left(\mathrm{T}_{\mathrm{imp}}=\mathrm{RT}\right)$ at the high dose rate results from annealing of damage, which in turn is caused by ion beam heating of the sample. The increase of the $\mathrm{H}_{\mathrm{sp}}$ value at $\mathrm{T}_{\mathrm{imp}}=1000{ }^{\circ} \mathrm{C}$ can also be explained by the ion-beam induced temperature increase. Studies on GaN decomposition in vacuum show that significant decomposition starts at $\mathrm{T}>1050^{\circ} \mathrm{C}$ [11]. It has also been shown that nitrogen evaporates faster than gallium in this temperature range. Thus, the high dose rate beam raises the sample temperature into the regime where enhanced decomposition of $\mathrm{GaN}$ takes place. Therefore, the observed increase in the height of the surface peak and its width may be due to the effect of nitrogen loss during ion implantation. Examination of the sample surface using an optical microscope and an SEM shows that the surface is smooth and featureless. No Ga droplets were observed, probably because the thickness of the decomposed layer is insignificant for this effect to occur or because congruent evaporation takes place.

\section{Conclusion}

We have used RBS/C spectroscopy to comprehensively study the impact of implantation temperature on the accumulation of radiation defects in $\mathrm{GaN}$ during $\mathrm{Ar}^{+}$ implantation. Two disordered regions were identified in the damage depth distribution: the surface peak and the bulk damage peak. A pronounced difference between the damage build up behavior in these regions was found. The height of the surface peak representing the amount of the disorder in the Ga sublattice on the sample surface decreases with increasing implantation temperature and approaches the magnitude corresponding to an unimplanted sample. This behavior indicates that radiation damage on the sample surface is effectively removed by implantation at elevated temperatures. The amount of disorder in the bulk region demonstrates retrograde behavior with implantation temperature. We believe that the damaged region with high Ar concentration may serve as a nucleation site for a type of defect responsible for the reverse annealing feature. It has been shown that the temperature range wherein the reverse annealing regime occurs depends on the dose rate and its shift towards lower implantation temperatures results from extra heating of the sample during the high dose rate implantation. This result demonstrates the importance of careful substrate temperature measurements during high-temperature ion implantation.

\section{ACKNOWLEDGMENTS}

The authors would like acknowledge D. K. Hensley for the assistance during RBS/C analysis and Drs. S. $P$. Withrow and $O$. W. Holland for valuable discussions.

\section{REFERENCES}

[1] N. Papanicolau, M. V. Rao, B. Molnar, J. Tucker, A. Edwards, O. W. Holland, M. C. Ridgway, Nucl. Instrum. Methods B 148, 416 (1999).

[2] S. J. Pearton, J. C. Zolper, R. J. Shul, F. Ren, J. Appl. Phys. 86, 1 (1998).

[3] S. O. Kucheyev, J. S. Williams, J. Zou, C. Jagadish, G. Li, Nucl. Instrum. Methods B 178, 209 (2001).

[4] C. Liu, A. Wenzel, K. Volz, B. Rauschenbach, Nucl. Instrum. Methods B 148, 369 (1999).

[5] N. Parikh, A. Suvkhanov, M. Lioubtchenko, E. Carlson, M. Bremser, D. Bray, R. Davis, J. Hunn, Nucl. Instrum. Methods B 127/128, 463 (1997).

[6] A. Wenzel, C. Liu, B. Rauschenbach, Mater. Sci. Eng. B 59, 191 (1999).

[7] L. Eriksson, J. A. Davies, N. G. E. Johansson, J. W. Mayer, J. Appl. Phys. 40, 842 (1969).

[8] S. T. Picraux, J. E. Westmoreland, J. W. Mayer, R. R. Hart, O. J. Marsh, Appl. Phys. Lett. 14, 7 (1969).

[9] T. E. Hynes, O. W. Holland, Appl. Phys. Lett. 59, 452 (1991).

[10] L. C. Feldman, J. M. Mayer, S. T. Picraux, "Materials Analysis by Ion Channeling", Academic Press, 117-135 (1982)

[11] J Hong, JW Lee, CB Vartuli, CR Abernathy, JD MacKenzie, SM Donovan, SJ Pearton, JC Zolper, J. Vac. Sci. Technol. A 15, 797-801 (1997).

\section{FIGURES}




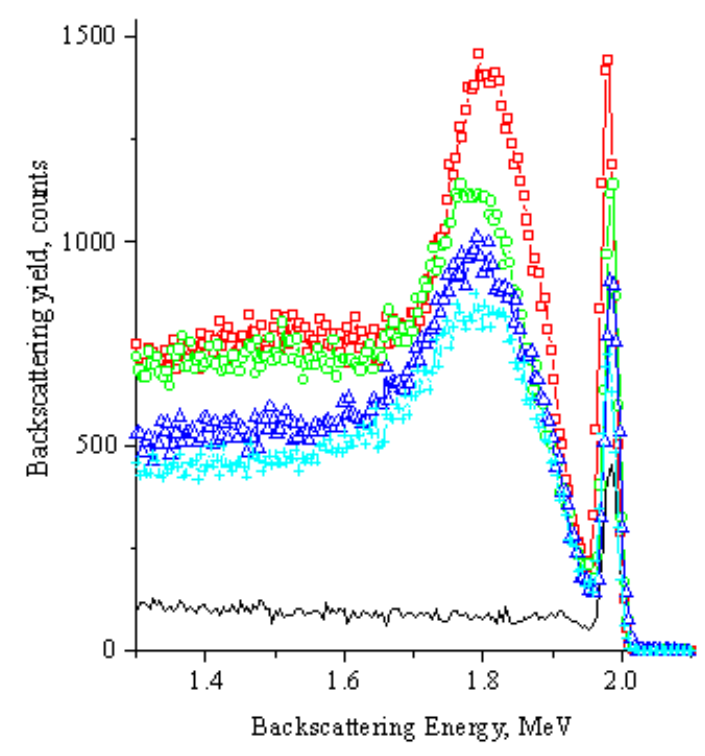

Figure 1a. RBS/C spectra of GaN implanted with $150 \mathrm{keV} \mathrm{Ar}^{+}$ to the dose of $3 \times 10^{15} \mathrm{~cm}^{-2}$ at different temperatures: RT [square](red), $150{ }^{\circ} \mathrm{C}-\wedge$ (green), $300{ }^{\circ} \mathrm{C}-\Delta$ (dark blue), $500{ }^{\circ} \mathrm{C}$ - + (light blue). Black solid line corresponds to an unimplanted sample.

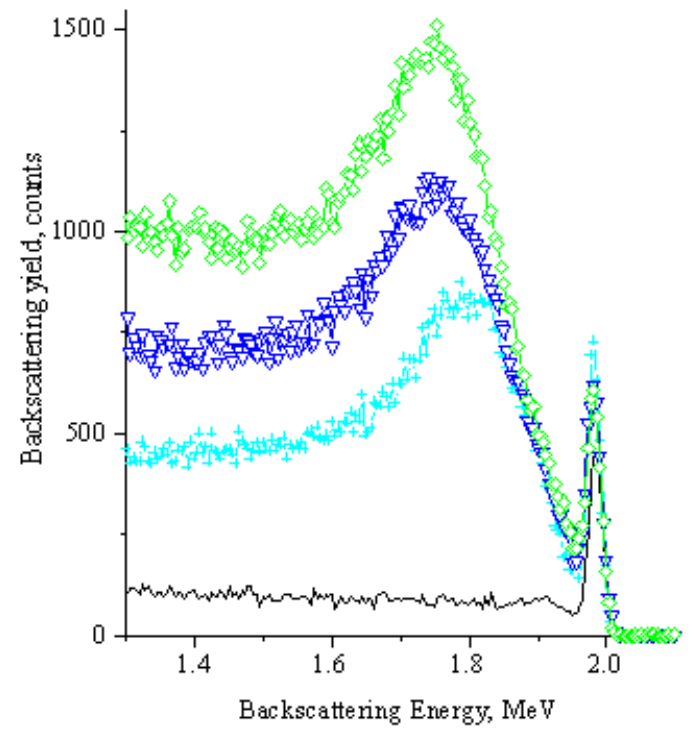

Figure 1b. RBS/C spectra of GaN implanted with $150 \mathrm{keV} \mathrm{Ar}^{+}$ to the dose of $3 \times 10^{15} \mathrm{~cm}^{-2}$ at different temperatures: $500{ }^{\circ} \mathrm{C}-+$ (light blue), $600{ }^{\circ} \mathrm{C}-\nabla$ (dark blue), $700{ }^{\circ} \mathrm{C}-\diamond$ (green). Black solid line corresponds to an unimplanted sample.

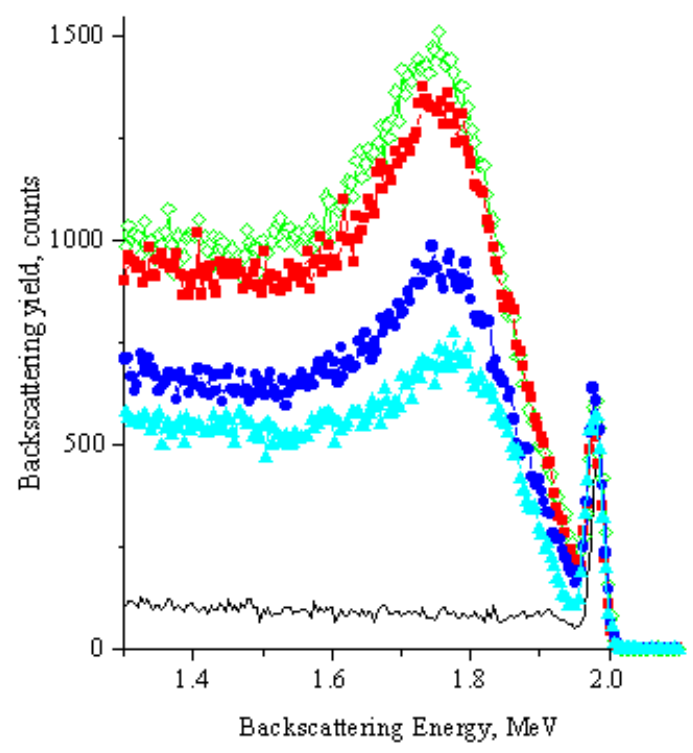

Figure 1c. RBS/C spectra of GaN implanted with $150 \mathrm{keV} \mathrm{Ar}^{+}$ to the dose of $3 \times 10^{15} \mathrm{~cm}^{-2}$ at different temperatures: $700{ }^{\circ} \mathrm{C}$ $\diamond$ (green; $800{ }^{\circ} \mathrm{C}$-[square] (red), $900{ }^{\circ} \mathrm{C}-\bullet$ (dark blue), 1000 ${ }^{\circ} \mathrm{C}-\Delta$ (light blue). Black solid line corresponds to an unimplanted sample.

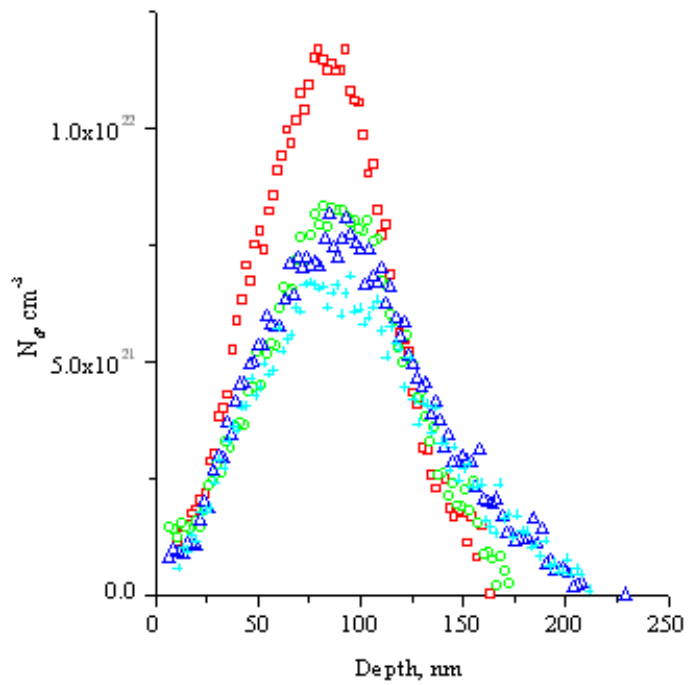

Figure 2a. The depth distribution of damage, $\mathrm{N}_{\mathrm{d}}(\mathrm{z})$, in $\mathrm{GaN}$ implanted with $150 \mathrm{keV} \mathrm{Ar}^{+}$at different implantation temperatures obtained using equation (1): RT - [square] (red), $150{ }^{\circ} \mathrm{C}$ - o (green), $300{ }^{\circ} \mathrm{C}-\Delta$ (dark blue), $500{ }^{\circ} \mathrm{C}-+$ (light blue). 


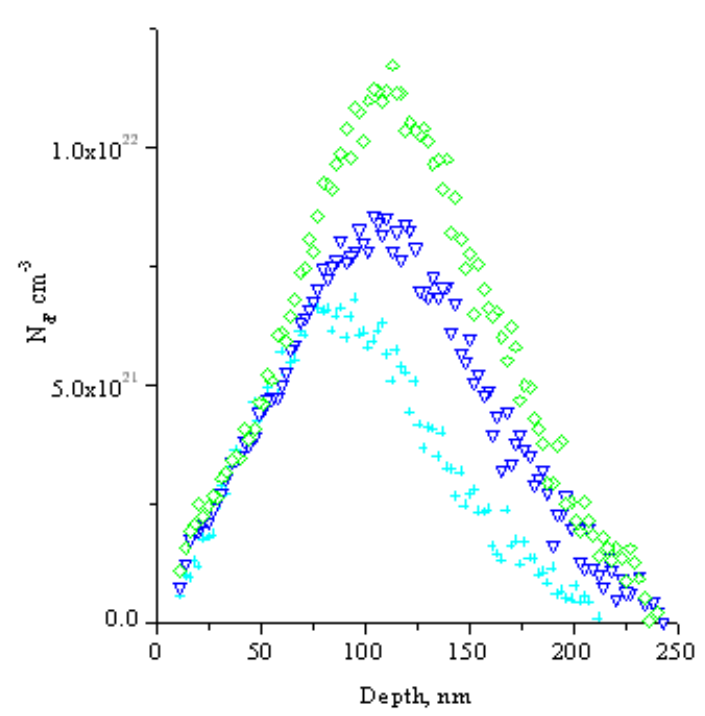

Figure $2 b$. The depth distribution of damage, $\mathrm{N}_{\mathrm{d}}(\mathrm{z})$, in $\mathrm{GaN}$ implanted with $150 \mathrm{keV} \mathrm{Ar}^{+}$at different implantation temperatures obtained using equation (1): $500{ }^{\circ} \mathrm{C}-+$ (light blue), $600{ }^{\circ} \mathrm{C}-\nabla$ (dark blue), $700{ }^{\circ} \mathrm{C}-\diamond$ (green).

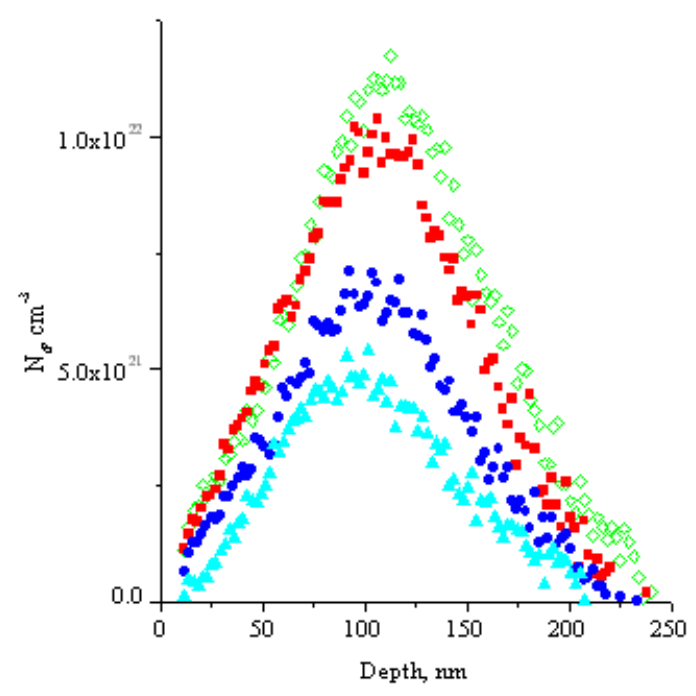

Figure 2c. The depth distribution of damage, $\mathrm{N}_{\mathrm{d}}(\mathrm{z})$, in $\mathrm{GaN}$ implanted with $150 \mathrm{keV} \mathrm{Ar}^{+}$at different implantation temperatures obtained using equation (1): $700{ }^{\circ} \mathrm{C}-\diamond$ (green), $800{ }^{\circ} \mathrm{C}$ - [square] (red), $900{ }^{\circ} \mathrm{C}-\bullet$ (dark blue), $1000{ }^{\circ} \mathrm{C}-\Delta$ (light blue).

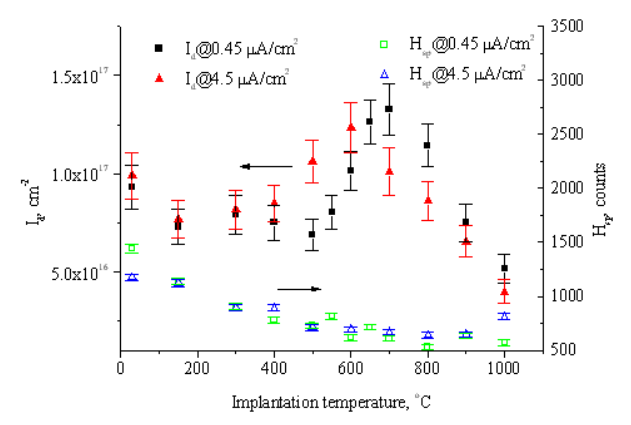

Figure 3. The integrated damage in the bulk peak, $\mathrm{I}_{\mathrm{d}}$, and the height of the surface peak, $\mathrm{H}_{\mathrm{sp}}$, as a function of the implantation temperature for two dose rates: 0.45 and $4.5 \mu \mathrm{A} /$ $\mathrm{cm}^{2}$. 